\title{
Development and validation of freshwater sediment quality assessment guidelines for trace elements in Korea
}

\author{
Dal Rae Jin, Chang-Hoon Lee ${ }^{2}$, Chan-Kook Kim², Seong-Dae Moon ${ }^{3}$, In Ae Huh', Suhyun Kim², \\ Min-Seung Park ${ }^{2}$, Jong-Hyeon Lee ${ }^{1,2^{+}}$ \\ ${ }^{1}$ School Water Environmental Engineering Research Division, National Institute of Environmental Research, Korea \\ ${ }^{2}$ Research Institute of Environmental Health and Safety (RIEHS), EH R\&C Co. Ltd., Korea \\ ${ }^{3}$ Institute of Environmental Safety and Protection, NeoEnBiz Co., Korea
}

\section{ABSTRACT}

Sediment quality assessment guidelines(SQAGs) for seven trace elements were suggested to build an assessment system of freshwater sediment quality for a regulatory program in Korea. In this study, current one-step SQAGs were divided into three levels based on the probability of toxicity occurrence, namely, the threshold-effect-level(TEL), the probable-effect-level(PEL), and the apparent-effect-threshold(AET). A sediment toxicity database consisting of field-collected sediments and toxicity results from three different species were used to derive TEL, PEL, and AET. The ambient background concentrations of trace elements in freshwater sediments were used instead of the TEL values because TEL values were lower than the ambient background levels. To validate the reliability of the new SQAGs, a separate sediment toxicity database based on G. sobaegensis was used. When the mean quotient value for the PEL was 0.34 , the reliability reached a maximum of $87 \%$ with a positive predictive value of $94 \%$ and a negative predictive value of $85 \%$. These results showed the newly derived SQAGs were very useful for assessing and predicting the toxicity of field sediments in Korea. Finally, ambient background concentrations, a mean quotient of PEL of 0.34, and AETs were used to classify the quality of the field-collected sediments into four categories.

Keywords: Indigenous test species, Reliability, Sediment quality assessment guidelines, Sediment toxicity database, Trace elements

\section{Introduction}

Sediment quality assessment guidelines (SQAGs) for the protection of benthic organisms in freshwater sediments in Korea were firstly issued in 2012 to assess chemical monitoring data of sediments, but have so far only been used to identify the apparently severe conditions of sediment quality. The SQAGs for seven trace elements $(\mathrm{Cu}, \mathrm{Pb}, \mathrm{As}, \mathrm{Hg}, \mathrm{Zn}, \mathrm{Cd}$, and $\mathrm{Cr}$ ) were directly adopted from either the cleanup screening level (CSL) of Washington State, USA [1] or the severe effect level (SEL) of Ontario, Canada [2]. Other types of SQAGs, such as effect range low (ERL) - effect range median (ERM) [3] and TEL-PEL [4] were not accepted for the assessment of sediment quality because the ERL and TEL values for some trace elements were lower than the ambient background concentrations of trace elements in Korean freshwater sediments.

After the interim SQAGs for trace elements were first issued in 2012, the Korean Ministry of Environment (MoE) launched a long-term project involving nationwide assessment and management systems for contaminated sediments in freshwater environments. This project included chemical monitoring of trace element contamination in sediments in major rivers and lakes, establishing the background concentration of each trace element, developing sediment toxicity testing methods using Korean indigenous species, and deriving multilevel SQAG values while considering the characteristics of aquatic ecosystems and the background concentrations of trace elements in Korea.

The methodology for the derivation of SQAGs was adopted from previous methods applied to SQAGs that were based on the probability of toxicity occurrence, namely the threshold effect level (TEL), probable effect level (PEL), and apparent effect threshold (AET) $[4,5]$. To derive the SQAGs for trace elements in Korean freshwater sediments, both chemical and ecotoxicological databases were es-
This is an Open Access article distributed under the terms of the Creative Commons Attribution Non-Commercial License (http://creativecommons.org/licenses/by-nc/3.0/) which permits unrestricted non-commercial use, distribution, and reproduction in any medium, provided the original work is properly cited.

Copyright (C) 2022 Korean Society of Environmental Engineers
Received November 24, 2020 Accepted July 04, 2021

${ }^{\dagger}$ Corresponding author

E-mail: j.lee@ehrnc.com

Tel: +82- 32-677-0852 Fax: +82-70-8610-0852

ORCID: 0000-0002-9090-2192 
tablished using three benthic species. As part of the development of toxicity testing methodologies, which were performed in parallel during the project, two Korean indigenous species, Gammarus sobaegensis (amphipod) and Chironomus kiiensis (chironomid), were used to assess the toxicity of field-collected sediments. Along with these two species, the North American amphipod Hyalella azteca was also to establish an ecotoxicological database.

In 2015, three different types of SQAGs for eight trace elements ( $\mathrm{Hg}, \mathrm{Cd}, \mathrm{As}, \mathrm{Ni}, \mathrm{Pb}, \mathrm{Cu}, \mathrm{Cr}$, and $\mathrm{Zn}$ ) were derived for the purpose of classifying sediment quality and used to improve sediment assessment and management as a regulatory program of the Korean MoE. This paper reports on the process of deriving and validating these SQAGs.

\section{Materials and Methods}

\subsection{Procedure for the Development of Freshwater SQAGs in Korea}

Consensus-based SQAG approach [6] was used to develop freshwater SQAGs in Korea. The background concentrations of trace elements in Korean freshwater sediments were incorporated into the derivation process of SQAGs. A sediment toxicity database was built using two indigenous species, Gammarus sobaegensis and Chironomus kiiensis, and the international standard test species Hyalella azteca. In addition, the SQAG values were validated using an independent sediment toxicity database for $G$. sobaegensis.

Fig. S1 shows the procedure used to derive and validate the freshwater SQAGs for trace elements in Korea. The first step was to collect the data to build the sediment toxicity database. The second step was to screen the sediment toxicity database using trace element concentrations in nontoxic samples and the background concentrations in river and lake sediments in Korea. The third step was to derive three different types of SQAG values corresponding to low, high, and very high probabilities of toxicity for the eight trace elements. The fourth step was to validate the derived SQAG values using the independent sediment toxicity database and suggest the use of SQAGs in the national sediment quality assessment and management framework.

\subsection{Data Collection}

\subsubsection{Sampling}

96 sampling sites were selected in streams and rivers in order to include the whole range of contaminant levels of trace elements in sediments including highly contaminated industrial complexes. .Highly contaminated sampling sites were selected based on previous studies [7], which include Gyeonggi-do, Chungcheong-do and Gyeongsang-do (Table S1).

A reference sediment was collected from uncontaminated site in Wahyeon, Geoje Island located at the southern part of Korean peninsula. At each location, the surface sediment in the top 5 cm was collected using a plastic scoop or a ponar grab sampler. Considering the heterogeneity of sediment distribution, more than 10 separated samples were pooled and mixed homogeneously. Sediment samples were transferred into a polyethylene bag, transported to the laboratory, and stored in a refrigerator at $4^{\circ} \mathrm{C}$ until chemical analyses and toxicity tests were performed.

\subsubsection{Chemical analyses}

Chemical analyses were performed following the standard operational protocol of the Korean MoE (2011). To remove larger particles, wet sediments were passed through a $150 \mu \mathrm{m}$ sieve and the passed particles were collected and dried. Approximately $0.2 \mathrm{~g}$ of dried sediment was ground with a mortar and digested by mixed acids $\left(\mathrm{HNO}_{3} / \mathrm{HF} / \mathrm{HClO}_{4}=4: 4: 1\right)$. Trace element concentrations (Cd, As, $\mathrm{Ni}, \mathrm{Pb}, \mathrm{Cu}, \mathrm{Cr}, \mathrm{Zn}$ ) were determined using inductively coupled plasma-atomic emission spectrometry (ICP-OES) and inductively coupled plasma-mass spectrometry (ICP-MS). The concentration of $\mathrm{Hg}$ was determined using a thermal decomposition atomic absorption spectrometry (TDAAS, model: DMA-80). The accuracy for each batch of sediment samples was verified with concomitant analyses of certified reference materials, including 280R and 1646a. The certificated reference materials (CRMs) analyzed throughout the study were within these certified ranges. A blank was assessed in triplicate for each batch which confirmed that the trace elements were not contaminated. The samples were checked for trace element contamination approximately every 10 samples for each batch; the relative standard deviation (RSD) was less than $10 \%$.

\subsubsection{Toxicity testing}

Toxicity tests were performed using two Korean indigenous species (an amphipod, Gammarus sobaegensis and a chironomid, Chironomus kiiensis) and an international standard test species (North American amphipod, Hyalella azteca). G. sobaegensis is a dominant amphipod which inhabits fine surface sediments in the upper streams of the Han River in the Korean peninsula. Some basic toxicological studies were carried out for this species [8, 9]. Standardized test conditions and acute toxicity test procedures for this species were established by the National Institute of Environmental Research in Korea [10]. Organisms for the toxicity tests were captured in the Gapyeong stream (38 $57^{\circ} 33^{\prime \prime} \mathrm{N}, 127^{\circ} 30^{\prime} 31^{\prime \prime}$ E) and acclimated to laboratory conditions for more than 7 days. Only organisms that were able to pass through $2 \mathrm{~mm}$ mesh but were prevented from passing through $1 \mathrm{~mm}$ mesh were used for the toxicity tests. Sediment samples were press-sieved with a 1 $\mathrm{mm}$ mesh to remove large particles and organic debris. Approximately $175 \mathrm{~mL}$ of sediment was transferred into a $1 \mathrm{~L}$ glass beaker, and then $800 \mathrm{~mL}$ of reconstituted water (80-150 mg $\mathrm{CaCO}_{3} / \mathrm{L}$ ) was injected carefully so as not to disturb the sediment surface. After aerating for $24 \mathrm{~h}$, the $\mathrm{pH}$, dissolved oxygen (DO), and total $\mathrm{NH}_{4}{ }^{+}$concentration of the overlying water was measured. Ten individual $G$. sobaegensis microbes were transferred into 1 of 4 replicated beakers per sample. Beakers were placed in an incubator at a temperature of $20 \pm 2^{\circ} \mathrm{C}$ and with a photoperiod of $16 \mathrm{Light} / 8 \mathrm{Dark}$ for $10 \mathrm{~d}$. After exposure, organisms were removed from the sediment by sieving with a $1 \mathrm{~mm}$ mesh.

C. kiiensis occurs in organic-rich, lentic zones of Korean rivers and lakes. In addition, $C$. kiiensis is the most frequently observed species of indigenous aquatic invertebrates in Korea [8]. Approximately $100 \mathrm{~mL}$ of sediment was transferred into a 300 $\mathrm{mL}$ glass beaker, and then $175 \mathrm{~mL}$ of reconstituted water (80-150 mg $\mathrm{CaCO}_{3} / \mathrm{L}$ ) was injected carefully so as not to disturb the sediment surface. Ten individual $C$. kiiensis microbes were transferred into 

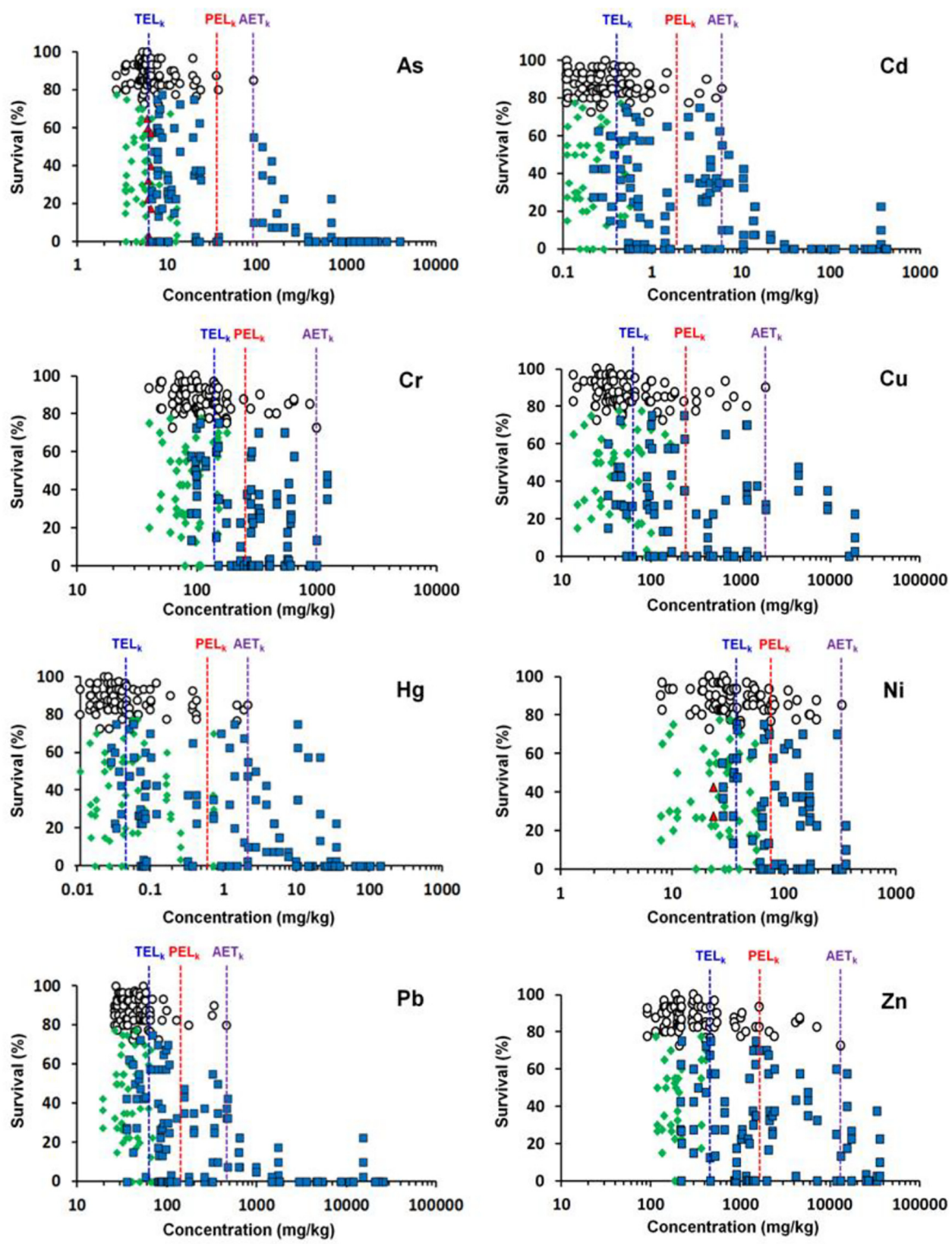

Fig. 1. Toxicity data used to derive sediment quality assessment guidelines (SQAGs), screened-out data, and SQAGs for each trace element (open circles represent nontoxic data, blue squares represent selected toxic data, green diamonds represent data screened out by nontoxic data and red triangles represent data screened out by the background concentration. TEL $—$ threshold effect level; PEL - probable effect level; $\mathrm{AET}_{\mathrm{k}}$ - apparent effect threshold).

1 of 4 replicated beakers per sample. The beakers were placed in an incubator at a temperature of $23^{\circ} \mathrm{C}$ and with a photoperiod of 16 Light/8 Dark for $10 \mathrm{~d}$ [8]. Tests using H. azteca were performed according to United States environmental protection agency (USEPA 600/R-99/064) [11].

The toxicity test results were classified as toxic or nontoxic based on two criteria, i.e., absolute mortality as well as the statistical difference of mortality between the test sediments and the reference sediment. If the mortality for a test sediment exceeded $20 \%$, the test sediment was classified as toxic. If the mortality was less than $20 \%$, the test results were compared between the experimental and control groups using Dunnett's $t$-test. If the $p$-value of the $t$-test was smaller than 0.05 , the toxicity test results were classified as toxic, even if the mortality value was less than $20 \%$.

\subsection{Data Screening}

Data screening process is necessary to derive SQAG values from the sediment toxicity database of the field-collected sediments [4, 
5]. Some toxic sediment samples contained lower trace element concentrations than the median concentration of nontoxic sediments in each watershed. The trace element concentrations of other toxic samples were lower than the background concentrations of trace elements in rivers and lakes in Korea [12]. In these cases, the sediment toxicity could have resulted from other, sediment-associated pollutants that were not trace elements. These kinds of toxic sediment samples were screened out to assess the concentration-response relationship between trace element concentration and sediment toxicity.

\subsection{SQAGs Derivation}

An eco-epidemiological approach based on the concentration-response relationship as observed from the field-collected sediment toxicity database was applied to derive freshwater SQAGs in Korea. Similar to the logistic regression analysis, a binary outcome, such as a sediment being toxic or nontoxic, was used as a response variable for the concentration-response relationship. The eco-epidemiologically-derived SQAGs were useful to predict the toxicity (toxic or nontoxic) of field-collected sediment samples in which other sediment-associated pollutants that were not trace elements could contribute toward sediment toxicity. In this study, the probability of toxicity in field-collected sediments was classified by three different levels of SQAG values, namely, threshold effect level $\left(\mathrm{TEL}_{\mathrm{k}}\right)$, probable effect level $\left(\mathrm{PEL}_{\mathrm{k}}\right)$, and apparent effect threshold $\mathrm{AET}_{\mathrm{k}}$. We used the framework of TEL, PEL, and AET as the indicator of the probability of sediment toxicity: low, high, and very high, respectively. According to the definition of $\mathrm{AET}_{\mathrm{k}}$, above $\mathrm{AET}_{\mathrm{k}}$, the probability of sediment toxicity is very high about $100 \%$ within our sediment toxicity database. Below $\mathrm{TEL}_{\mathrm{k}}$, the probability of sediment toxicity is low, e.g., less than $10 \%$. Between $\mathrm{TEL}_{\mathrm{k}}$ and $\mathrm{AET}_{\mathrm{k}}$, we added the transition zone from low to high probability using $\mathrm{PEL}_{\mathrm{k}}$. This approach is very similar to the generalized concentration-response model for contaminated sediments [13]. The calculation methods for $\mathrm{TEL}_{\mathrm{k}}$, and $\mathrm{PEL}_{\mathrm{k}}$ were according to McDonald [14] and for $\mathrm{AET}_{\mathrm{k}}$, the method was according to Barrick [5].

According to Wenning [15], $\mathrm{TEL}_{\mathrm{k}}$ and $\mathrm{AET}_{\mathrm{k}}$ are useful in the identification of nontoxic sediments and toxic sediments, respectively. It is impossible to derive the cutoff point for toxic and nontoxic sediments using the SQAG value for individual trace elements or pollutants. In this study, the mean $\mathrm{PEL}_{\mathrm{k}}$ quotient $\left(\mathrm{mPEL}_{k} \mathrm{Q}\right)$ for eight trace elements was used to predict the probability of a mixture's toxicity in Korean freshwater sediment [16].

$$
m P E L_{k} Q=\frac{\sum_{i=1}^{n}\left(\frac{E C_{i}}{P E L_{i}}\right)}{n}
$$

where $E C_{i}$ is the individual trace elements of concentration, $\mathrm{PEL}_{\mathrm{i}}$ is the $\mathrm{PEL}_{\mathrm{k}}$ of individual trace elements, and $n$ is the number of individual trace elements $\mathrm{PEL}_{\mathrm{k}}$. The cutoff value of $\mathrm{mPEL}_{\mathrm{k}} \mathrm{Q}$ to predict the probability of toxicity in the field-collected sediments was selected as the maximum value of overall reliability (OR), according to Guunarsson and Lanke (Table S1) [17]. A case study including more accurate and robust presentation of the reliability indicator for SQGs [18], which showed the results of evaluation of various SQG approaches based on the reliability indicator similar to that of this study.

\subsection{Field Validation Using Independent Toxicity Database}

The newly derived SQAGs needed to be tested regarding their effectiveness in predicting the probability of toxicity in sediments collected from urban rivers near cities or industrial complexes. To validate the SQAG values, the negative predictive value (NPV) for $\mathrm{TEL}_{\mathrm{k}}$, the positive predictive value (PPV) for $\mathrm{AET}_{\mathrm{k}}$, and the overall reliability (OR), as well as the NPV and PPV for m-PELQ were checked using the field-collected sediment toxicity database. Based on the performance of $\mathrm{TEL}_{\mathrm{k}}, \mathrm{AET}_{\mathrm{k}}$, and $\mathrm{m}-\mathrm{PELQ}_{\mathrm{k}}$, the applicability of these SQAGs was suggested for the national sediment quality assessment and management framework.

\section{Results and Discussion}

\subsection{Sediment Toxicity Database: Trace element Contamination Levels in Toxic and Nontoxic Sediments near Urban Rivers in Korea}

Out of 73 samples, the chemical concentrations of eight trace elements are summarized in Table 1 . The concentrations of $\mathrm{Cd}, \mathrm{Cu}$, and $\mathrm{Hg}$ varied greatly, with more than 1,000-fold differences between the minimum and maximum concentrations. On the other hand, $\mathrm{Cr}$ and Ni showed the least variation, with less than 100-fold differences. Among the eight trace elements, the average concentration of $\mathrm{Zn}(3,160 \mathrm{mg} / \mathrm{kg})$ was highest, followed by $\mathrm{Cu}(684$ $\mathrm{mg} / \mathrm{kg}$ ) and $\mathrm{Pb}(368 \mathrm{mg} / \mathrm{kg})$, while that of $\mathrm{Hg}(1.71 \mathrm{mg} / \mathrm{kg})$ was the lowest. The proportions of toxic sediments to $G$. sobaegensis, C. kiiensis, and $H$. azteca were $45 \%, 60 \%$, and $79 \%$, respectively (Table S2). The database used to derive the SQAGs contained a fairly balanced number of toxic and nontoxic sediments, as this reduces unintended statistical biases in calculation of predictive reliability. Altogether, for the three test species, the number of toxic samples was 135 . There were 1.2-6.1-fold differences in the chemical concentrations of trace elements between nontoxic and toxic sediments. The ratio of concentrations of toxic to nontoxic sediments ( $\mathrm{T} / \mathrm{N}$ ratio, Table 2) for $G$. sobaegensis was generally higher than $C$. kiiensis and $H$. azteca. Among the eight trace elements, the $\mathrm{T} / \mathrm{N}$ ratio was higher for $\mathrm{Cd}, \mathrm{Cu}, \mathrm{Hg}$, and $\mathrm{Zn}$, but lower for $\mathrm{As}, \mathrm{Cr}, \mathrm{Ni}$, and $\mathrm{Pb}$.

\subsection{Screening of Sediment Toxicity Database for the Derivation of SQAGs}

Prior to the derivation of the guideline values, some of the toxic data were screened out in order to remove any toxic data suspected not to have been caused by trace elements. This screening was performed in two steps (Table 3). First, toxic data with trace element concentrations lower than the geometric mean of the nontoxic data in each watershed were excluded. In this step, $25-46 \%$ of toxic data were excluded from the database. Second, toxic data with trace element concentrations lower than the background concentration were excluded. Here, the median concentration of trace elements in freshwater sediments [7] was used as the background concentration for the data screening. In this step, ten pieces of 
Table 1. Minimum, Maximum, Median, Average, and Standard Deviation (SD) Values of Trace Element Concentrations (mg/kg) in Sediments $(n=73)$ for the Derivation of Sediment Quality Assessment Guidelines

\begin{tabular}{|c|c|c|c|c|c|}
\hline Trace element & Minimum & Maximum & Median & Average & SD \\
\hline As & 1.80 & 910 & 5.96 & 27.8 & 126 \\
\hline $\mathrm{Cd}$ & 0.10 & 319 & 0.35 & 8.24 & 44.4 \\
\hline $\mathrm{Cr}$ & 16.7 & 1,210 & 101 & 191 & 223 \\
\hline $\mathrm{Cu}$ & 13.4 & 13,700 & 59.1 & 684 & 2,240 \\
\hline $\mathrm{Hg}$ & 0.01 & 41 & 0.06 & 1.71 & 6.18 \\
\hline $\mathrm{Ni}$ & 7.83 & 232 & 33.9 & 52.4 & 48.4 \\
\hline $\mathrm{Pb}$ & 14.9 & 13,700 & 44.5 & 368 & 1,760 \\
\hline $\mathrm{Zn}$ & 84.6 & 36,000 & 296 & 3,160 & 7,440 \\
\hline
\end{tabular}

Table 2. Geometric Means of Trace Element Concentrations $(\mathrm{mg} / \mathrm{kg})$ in Nontoxic and Toxic Sediments, and the Ratio of Concentrations between Toxic and Nontoxic Sediments (T/N) for Each Test Organism

\begin{tabular}{|c|c|c|c|c|c|c|c|c|c|}
\hline \multirow{2}{*}{ Trace element } & \multicolumn{3}{|c|}{ Gammarus sobaegensis } & \multicolumn{3}{|c|}{ Chironomus kiiensis } & \multicolumn{3}{|c|}{ Hyalella azteca } \\
\hline & Nontoxic & Toxic & $\mathbf{T} / \mathbf{N}$ & Nontoxic & Toxic & $\mathbf{T} / \mathbf{N}$ & Nontoxic & Toxic & $\mathbf{T} / \mathbf{N}$ \\
\hline As & 5.93 & 8.61 & 1.5 & 4.95 & 8.83 & 1.8 & 5.79 & 7.38 & 1.3 \\
\hline $\mathrm{Cd}$ & 0.31 & 1.02 & 3.3 & 0.30 & 0.77 & 2.6 & 0.22 & 0.67 & 3.1 \\
\hline $\mathrm{Cr}$ & 91.8 & 165 & 1.8 & 93.9 & 140 & 1.5 & 92.7 & 128 & 1.4 \\
\hline $\mathrm{Cu}$ & 49.5 & 214 & 4.3 & 60.1 & 131 & 2.2 & 34.1 & 126 & 3.7 \\
\hline $\mathrm{Hg}$ & 0.05 & 0.28 & 6.1 & 0.08 & 0.13 & 1.7 & 0.03 & 0.15 & 5.5 \\
\hline $\mathrm{Ni}$ & 29.8 & 49.7 & 1.7 & 33.7 & 40.3 & 1.2 & 25.3 & 41.6 & 1.6 \\
\hline $\mathrm{Pb}$ & 41.0 & 91.2 & 2.2 & 38.3 & 78.2 & 2.0 & 37.6 & 66.1 & 1.8 \\
\hline $\mathrm{Zn}$ & 270 & 1,338 & 5.0 & 315 & 811 & 2.6 & 250 & 685 & 2.7 \\
\hline
\end{tabular}

Table 3. Numbers of Individual Data Screened Out by the Geometric Mean of Nontoxic Data and by the Background Concentration; The Remaining Data Were Selected for the Sediment Quality Assessment Guidelines (SQAGs)

\begin{tabular}{|c|c|c|c|c|c|}
\hline \multirow{2}{*}{$\begin{array}{l}\text { Trace } \\
\text { element }\end{array}$} & \multirow{2}{*}{$\begin{array}{l}\text { Background Concentration }{ }^{1} \\
(\mathrm{mg} / \mathrm{kg})\end{array}$} & \multicolumn{4}{|c|}{ Numbers of Individual Data Before and After Screening } \\
\hline & & $\begin{array}{c}\text { Before } \\
\text { Screening }\end{array}$ & $\begin{array}{c}\text { Screened by Nontoxic } \\
\text { Data }\end{array}$ & $\begin{array}{l}\text { Screened by the } \\
\text { Background Concentration }\end{array}$ & $\begin{array}{c}\text { Finally Selected for } \\
\text { SQAGs }\end{array}$ \\
\hline As & 6.7 & 135 & 58 & 0 & 77 \\
\hline $\mathrm{Cd}$ & 0.16 & 135 & 56 & 4 & 75 \\
\hline $\mathrm{Cr}$ & 83 & 135 & 42 & 0 & 93 \\
\hline $\mathrm{Cu}$ & 28.4 & 135 & 47 & 0 & 88 \\
\hline $\mathrm{Hg}$ & 0.025 & 135 & 62 & 10 & 63 \\
\hline $\mathrm{Ni}$ & 25.3 & 135 & 52 & 0 & 83 \\
\hline $\mathrm{Pb}$ & 29.1 & 135 & 51 & 0 & 84 \\
\hline $\mathrm{Zn}$ & 143 & 135 & 34 & 0 & 101 \\
\hline
\end{tabular}

${ }^{1}$ Median concentration of freshwater sediments (NIER, 2011).

Hg data and four pieces of Cd data were excluded. After the screening, the final database for the derivation of SQAGs was confirmed. The number of selected toxic data pieces ranged from $63(\mathrm{Hg})$ to $101(\mathrm{Zn})$.

\subsection{Derivation of Freshwater SQAGs for Individual Trace elements}

Using the database of selected toxic and nontoxic data, the threshold effect concentration $\left(\mathrm{TEL}_{\mathrm{k}}\right)$, probable effect concentration $\left(\mathrm{PEL}_{\mathrm{k}}\right)$, and apparent effect threshold $\left(\mathrm{AET}_{\mathrm{k}}\right)$ were derived (Table 6). The SQAG values from highest to lowest were $\mathrm{Zn}>\mathrm{Cr}>\mathrm{Pb}>\mathrm{Cu}$ $>\mathrm{Ni}>\mathrm{As}>\mathrm{Cd}>\mathrm{Hg}$. $\mathrm{PEL}_{\mathrm{k}}$ was about 2-4 times higher than
$\mathrm{TEL}_{\mathrm{k}}$ for $\mathrm{Cr}, \mathrm{Ni}, \mathrm{Pb}$, and $\mathrm{Zn}$ and more than 4 times higher for As, $\mathrm{Cd}, \mathrm{Cu}$, and $\mathrm{Hg}$. $\mathrm{AET}_{\mathrm{k}}$ was about 2-4 times higher than $\mathrm{PEL}_{\mathrm{k}}$ for $\mathrm{As}, \mathrm{Cd}, \mathrm{Hg}, \mathrm{Ni}$, and $\mathrm{Pb}$ and more than 4 times higher for $\mathrm{Cr}$, $\mathrm{Cu}$, and Zn. Fig. 2 shows the toxicity data used for the SQAG derivation, as well as the screened-out data and the SQAGs for each trace element. For all of the trace elements, there were many toxic sites with concentration less than TEL. This implies that sediment toxicity cannot be explained by the concentration of single chemical, and the mixed effects of as many chemicals as possible such as organic chemicals should always be considered. There were also many sites with trace element concentrations higher than $\mathrm{AET}_{\mathrm{k}}$ for $\mathrm{As}, \mathrm{Cd}, \mathrm{Cu}, \mathrm{Hg}, \mathrm{Pb}$, and $\mathrm{Zn}$, indicating that these 


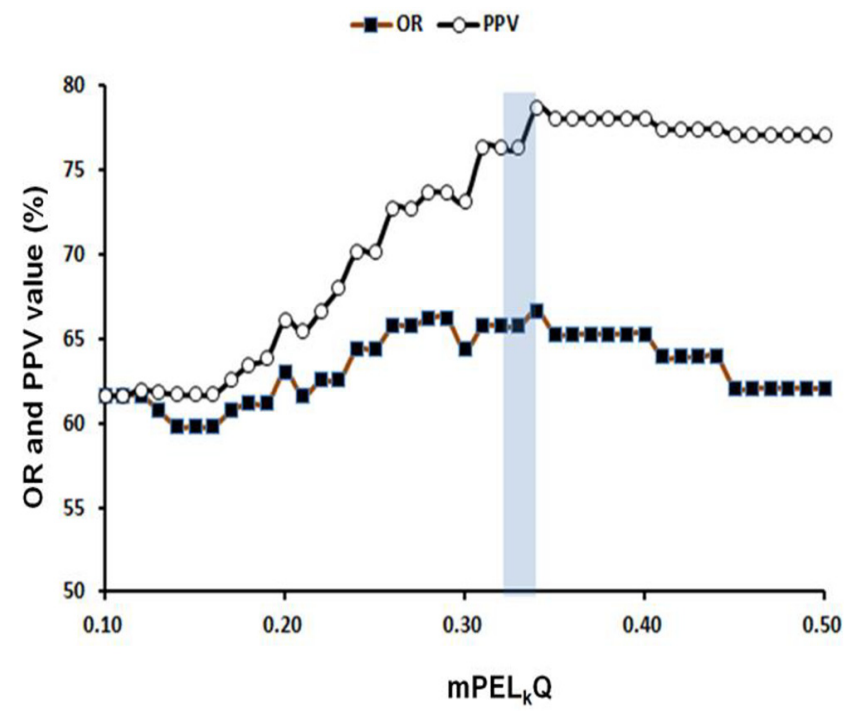

Fig. 2. Change in overall reliability $(\mathrm{OR})$ and positive predictive value (PPV) with increasing mean PEL quotient ( $\left.\mathrm{mPEL}_{k} \mathrm{Q}\right)$. See Materials and Methods for OR, PPV, and $\mathrm{mPEL}_{\mathrm{k}} \mathrm{Q}$ calculation methods.

trace elements may be major constituents of sources of toxicity in Korean freshwater sediments. The $\mathrm{AET}_{\mathrm{k}}$ and $\mathrm{PEL}_{\mathrm{k}}$ values of $\mathrm{Cr}$ and $\mathrm{Ni}$ could be increased by adding new data into the sediment toxicity DB because there were no toxic samples with sediment concentrations higher than the maximum of the nontoxic samples in the existing sediment toxicity database.

As shown in Table 4, LAET values are similar to PEC and $\mathrm{PEL}_{k}$, but HAET values are similar to $\mathrm{AET}_{\mathrm{k}}$. These results can be expected from our methods to derive $\mathrm{AET}_{\mathrm{k}}$ values. We used the sediment toxicity database from three species to derive $\mathrm{AET}_{\mathrm{k}}$. So our $\mathrm{AET}_{\mathrm{k}}$ values were similar to HAET. In the case of the Puget Sound Dredged Disposal Analysis (PSDDA) program, they used the AET approach to screen sediments proposed for dredging and suggested the maximum level (ML) values as the highest of 4 biological indicators such 10-d amphipod toxicity test [19]. The ML is similar to our $\mathrm{AET}_{\mathrm{k}}$ and HAET.

\subsection{Criteria for Mixture of Eight Trace elements to Discriminate between Toxic and Nontoxic Sediments}

Since the SQAG value of a single trace element could not be used to predict whether individual sediments were toxic or not, a new quotient to represent the potential effects of mixed chemicals i.e., the mean $\mathrm{PEL}_{\mathrm{k}}$ quotient $\left(\mathrm{mPEL}_{\mathrm{k}} \mathrm{Q}\right)$, was adopted. To maximize the predictability of the $\mathrm{mPEL}_{\mathrm{k}} \mathrm{Q}$ to discriminate between toxic and nontoxic sediments, the criteria were determined by evaluating the change in overall reliability (OR) and positive predictive value (PPV) in relation to varying $\mathrm{mPEL}_{\mathrm{k}} \mathrm{Q}$ values. The $\mathrm{OR}$ and PPV increased as the $\mathrm{mPEL}_{\mathrm{k}} \mathrm{Q}$ increased from 0.01 to 0.34 (Fig. 2). When $\mathrm{mPEL}_{\mathrm{k}} \mathrm{Q}$ increased to more than 0.34 , OR and NPV decreased. Therefore, the optimum value of $\mathrm{mPEL}_{\mathrm{k}} \mathrm{Q}$ as the criteria to discriminate between toxic and nontoxic sediments was 0.34 in Korean freshwater sediments near urban rivers and lakes.

The mean SQG quotients have been determined by calculating the arithmetic mean of the quotients derived by dividing the concentrations of chemicals in sediments by SQGs derived with empirical approaches, such as ERM, PEL, PEC and AET. The mean SQG quotients have been demonstrated to provide a reliable basis for classifying whole sediment samples as toxic and not toxic and formed an important component in the remedial action planning process at contaminated sediment sites [20]. A mean PEC quotient value of 0.31 has been suggested as the critical value (inflection point) by examining the distribution of both the mean PEC quotients and the toxicity test results [21]. Most of studies to establish the inflection point is to calibrate the mean SQG quotients to the matching results of toxicity tests. Using different ranges and intervals in the mean SQS quotients, until visual examinations and statistical analyses of the data indicated which of the cut points were most consistent [22]. These cut points identified 4 ranges and categories in chemical exposure: (1) Minimum, (2) Low, (3) Moderate, and (4) Maximum [23].

Until now, it was not suggested how to derive the cut points as an optimal value, but the general exposure-response relationships for the mean SQG quotients and laboratory toxicity tests [20, 24]. Based on the positive predictive value (PPV) or the incidence of toxicity for the mean SQG quotients, we cannot select any cut

Table 4. Comparison of Sediment Quality Assessment Guidelines Derived for Eight Trace Elements in Korean Freshwater Sediments (mg/kg) with Those Similar Guideline Values Already Published Elsewhere

\begin{tabular}{lccccccc} 
Trace element & TEL $_{\mathbf{k}}$ & TEC $^{\mathbf{1}}$ & $\mathbf{P E L}_{\mathbf{k}}$ & PEC $^{\mathbf{1}}$ & AET $_{\mathbf{k}}$ & LAET $^{\mathbf{2}}$ & HAET $^{\mathbf{2}}$ \\
$\mathrm{As}$ & 7.0 & 9.8 & 44.7 & 33 & 92.1 & 57 & 700 \\
$\mathrm{Cd}$ & 0.4 & 0.99 & 1.87 & 5.0 & 6.09 & 5.1 & 9.6 \\
$\mathrm{Cr}$ & 112 & 43 & 224 & 110 & 991 & 260 & 270 \\
$\mathrm{Cu}$ & 48 & 32 & 228 & 150 & 1,890 & 390 & 1,300 \\
$\mathrm{Hg}$ & 0.05 & 0.18 & 0.67 & 1.1 & 2.14 & 0.41 & 2.1 \\
$\mathrm{Ni}$ & 40 & 23 & 87.5 & 49 & 330 & 140 & 140 \\
$\mathrm{~Pb}$ & 59 & 36 & 154 & 130 & 459 & 450 & 660 \\
$\mathrm{Zn}$ & 363 & 120 & 1,170 & 460 & 13,000 & 410 & 1,600 \\
\hline
\end{tabular}

TEL $_{k}$ - threshold effect level; TEC-threshold effect concentration; $\mathrm{PEL}_{\mathrm{k}}$ — probable effect level; PEC-probable effect concentration; $\mathrm{AET}_{\mathrm{k}}$ apparent effect threshold; LAET-low AET; HAET-high AET

1: consensus based sediment quality guidelines(MacDonald et al 2000)

${ }^{2}$ : Washington State apparent effect threshold(Barrick et al 1988) 
point because the PPV of the mean SQG quotients increase with the increase of the mean SQG quotient. Using the overall reliability, we can derive a cut point for the mean SQG quotient with the maximum value of the OR. In this study, $\mathrm{mPEL}_{\mathrm{k}} \mathrm{Q}$ of 0.34 was derived as a cut point to discriminate between toxic and nontoxic sediments. The cut point (0.34) of $\mathrm{mPEL}_{\mathrm{k}} \mathrm{Q}$ as the screening tool, however, needs to be further validated by independent sediment chemistry and toxicity database.

\subsection{Field Validation Using Independent Sediment Toxicity Database}

Field validation was performed using an independent database displaying chemical analyses and toxicity tests for an additional set of sediment samples (71 sites) in urban rivers near cities or industrial complexes, which did not overlap with the database used for SQAG derivation. Toxicity to the Korean scud, Gammarus sobaegensis, was observed in $68 \%$ of sediments. With the results of chemical analyses, the negative predictive value (NPV), the positive predictive value (PPV), and the overall reliability (OR) of $\mathrm{PEL}_{\mathrm{k}}$ values for each trace element were calculated (Table 5). In general, the PPV was higher (over 0.8) and the NPV was lower (from 0.36 to 0.62 ). A high PPV demonstrated that the individual $\mathrm{PEL}_{\mathrm{k}}$ could be used to find toxic sediments. However, a low NPV meant that many samples with trace element concentrations not exceeding PEL $L_{k}$ were toxic, indicating that individual $\mathrm{PEL}_{\mathrm{k}}$ could not be used to find nontoxic sediments. As mentioned in section 3.3. toxicity of samples not exceeding $\mathrm{PEL}_{\mathrm{k}}$ may be due to chemicals not measured in this study, such as organic chemicals.

Table 5. Validation of $\mathrm{PEL}_{\mathrm{k}}$ for Individual Trace Elements

\begin{tabular}{llll}
\hline Trace Element & PPV & NPV & OR \\
\hline $\mathrm{As}$ & 0.88 & 0.39 & 0.51 \\
$\mathrm{Cd}$ & 0.95 & 0.62 & 0.79 \\
$\mathrm{Cr}$ & 0.84 & 0.38 & 0.51 \\
$\mathrm{Cu}$ & 0.93 & 0.50 & 0.68 \\
$\mathrm{Hg}$ & 1.00 & 0.37 & 0.45 \\
$\mathrm{Ni}$ & 0.81 & 0.36 & 0.46 \\
$\mathrm{~Pb}$ & 0.94 & 0.41 & 0.54 \\
$\mathrm{Zn}$ & 0.86 & 0.41 & 0.55 \\
\hline
\end{tabular}

PPV—positive predictive value;

NPV—negative predictive value; OR — overall reliability.
As a consequence, the OR was also lower (from 0.49 to 0.79 ), indicating that individual $\mathrm{PEL}_{\mathrm{k}}$ was not appropriate to discriminate between toxic and nontoxic sediments.

Contrary to individual $\mathrm{PEL}_{\mathrm{k}}$ values, high validity was observed for the mean PEL quotient $\left(\mathrm{mPEL}_{\mathrm{k}} \mathrm{Q}\right)$ value. We obtained 23 nontoxic and 48 toxic samples to study the validation. The $\mathrm{mPEL}_{\mathrm{k}} \mathrm{Q}$ values of $65 \%$ of the nontoxic samples were lower than 0.34 , whereas $98 \%$ of toxic samples had values higher than 0.34 . When the $\mathrm{mPEL}_{k} \mathrm{Q}$ value was 0.34, the PPV, NPV, and OR were as high as 0.94, 0.85, and 0.87 , respectively, indicating that the $\mathrm{mPEL}_{\mathrm{k}} \mathrm{Q}$ of 0.34 was a very useful criterion to discriminate between toxic and nontoxic sediments contaminated with trace elements in Korean freshwater environments. The SQAGs derived from the field-collected sediment toxicity database holding individual trace element data were not validated, but the mean quotient values for all of the trace elements were valid [15].

\subsection{Classification of Sediment Contamination Levels Using SQAGs for Individual Trace Elements}

From the derived SQAG values, we divided the contamination level of each trace element into four classes according to the probability of toxicity (Table 6). Class I represented a sediment contamination level of trace element lower than the $\mathrm{TEL}_{\mathrm{k}}$ values, showing a low probability of toxicity. When the $\mathrm{TEL}_{\mathrm{k}}$ value was lower than the background concentration, the background concentration was used as the upper limit of sediment concentration instead of the TEL. Since Korea has different values of background concentrations of trace elements in sediments between rivers and lakes, Class I was defined separately for rivers and lakes. In this study, the 95th percentile of natural sediments $[7,12]$ was used as the "ambient" background concentration for sediment quality classification. Class II was the sediment contamination level between the $\mathrm{TEL}_{\mathrm{k}}$ and the $\mathrm{PEL}_{\mathrm{k}}$ with a medium probability of toxicity. Class III was the sediment contamination level between the PEL $\mathrm{P}_{\mathrm{k}}$ and the $\mathrm{AET}_{\mathrm{k}}$ with a high probability of toxicity. Class IV was the sediment contamination level higher than the $\mathrm{AET}_{\mathrm{k}}$ with a very high probability of toxicity. In Table 6 , we introduced the classification of sediment contamination using individual SQAGs, which was not directly used to assess the toxicity of field-collected sediment with mixture of different types of contaminants including metals. Instead of individual SQAGs, we suggested the framework for sediment quality assessment and management based on the

Table 6. Classification of Sediment Contamination Level Using SQAGs for Individual Trace Elements

\begin{tabular}{lccccc}
\hline \multirow{2}{*}{ Trace element } & \multicolumn{2}{c}{ Sediment Contamination Level (mg/kg) } \\
\cline { 2 - 6 } & Class I (River) & Class I (Lake) & Class II & Class III & Class IV \\
\hline $\mathrm{As}$ & $<15$ & $<29$ & $<44.7$ & $<92.1$ & $>92.1$ \\
$\mathrm{Cd}$ & $<0.4$ & $<0.6$ & $<1.87$ & $<6.09$ & $>6.09$ \\
$\mathrm{Cr}$ & $<112$ & $<112$ & $<224$ & $<991$ & $>991$ \\
$\mathrm{Cu}$ & $<48$ & $<0.1$ & $<228$ & $<1,890$ & $>1,890$ \\
$\mathrm{Hg}$ & $<0.07$ & $<53$ & $<0.67$ & $<330$ & $>330$ \\
$\mathrm{Ni}$ & $<40$ & $<65$ & $<154$ & $<459$ & $>459$ \\
$\mathrm{~Pb}$ & $<59$ & $<363$ & $<1,170$ & $<13,000$ & $>13,000$ \\
$\mathrm{Zn}$ & $<363$ & & & $<$
\end{tabular}


probability of the toxicity of sediment as a mixture. According to the concepts of $\mathrm{TEL}_{\mathrm{k}}, \mathrm{PEL}_{\mathrm{k}}$, and $\mathrm{AET}_{\mathrm{k}}$, the $\mathrm{TEL}_{\mathrm{k}}$ and $\mathrm{AET}_{\mathrm{k}}$ should not be averaged, but selected as a minimized ( $\mathrm{TEL}_{\mathrm{k}}$ ) or maximized $\left(\mathrm{AET}_{\mathrm{k}}\right)$ values. PEL can be averaged as $\mathrm{MPEL}_{\mathrm{k}} \mathrm{Q}$ and were selected as a cut point (0.34) with the highest reliability to discriminate between toxic and nontoxic sediments.

\subsection{Sediment Quality Assessment Using SQAGs for Individual and Mixed Trace Elements}

The newly derived SQAGs for the eight trace elements were used to identify sediments unaffected by anthropogenic trace element contamination and severely contaminated sediments (Table S3). For a given site or sediment sample, if the contamination levels of all eight trace elements were Class I, the status of the trace element contamination of the sediment was "good", which is the ambient background concentration only affected by air deposition. If the contamination level of any trace element was Class IV, the status of the sediment was "very bad" with severe adverse effects; these should be managed by source control and via prevention of secondary pollution. Between the two zones easily identified by individual SQAGs, there was the gray zone, where the probability of toxicity was not affected by individual trace elements, but rather by mixtures of trace elements. In this study, in addition to the individual SQAGs derived for each trace element, the optimized $\mathrm{mPEL}_{k} \mathrm{Q}$ value (0.34) for the eight trace elements was used to discriminate between sediments with toxicity ("bad") and those without toxicity ("fair"). If the $\mathrm{mPEL}_{\mathrm{k}} \mathrm{Q}$ value calculated from each trace element concentration and Class II criteria is greater than 0.34 , the sediment is considered as "bad". If the sediment is categorized as "bad", the sediment needs to be comprehensively assessed by gradient sampling to identify the spatial scale and the severity of the contamination. In the case of a sediment graded as "fair", further monitoring was necessary to confirm sediment toxicity.

\section{Conclusions}

The SQAGs for eight trace elements in freshwater sediments in Korea were derived from a sediment toxicity database using two indigenous species and one standard test species. The sediments were validated using a separate sediment toxicity database, which was used to analyze SQAG reliability regarding the prediction of toxicity probabilities. The newly derived SQAGs (TEL $L_{k}$ and $\mathrm{AET}_{\mathrm{k}}$ ) for the individual trace elements could be used to identify severely contaminated sediments as well as sediments unaffected by anthropogenic trace element contamination. Contaminated sediments collected from urban rivers near cities and industrial complexes which are sediment monitoring network in Korea were used to verify the derived SQAGs. But, mine sediment has not been evaluated using the SQAGs and further research is necessary. The empirically derived $\mathrm{mPEL}_{\mathrm{k}} \mathrm{Q}$ value of 0.34 for the eight trace elements successfully predicted the toxicity probability of field-collected freshwater sediments in Korea, with an overall reliability of $87 \%$. Therefore, the $\mathrm{TEL}_{\mathrm{k}}, \mathrm{PEL}_{\mathrm{k}}$, and $\mathrm{AET}_{\mathrm{k}}$ values for individual trace elements and an $\mathrm{mPEL}_{\mathrm{k}} \mathrm{Q}$ value of 0.34 can be successfully applied to assess and manage the quality of freshwater surface sediments in Korea.

\section{Acknowledgments}

This research was funded by the National Institute of Environment Research (NIER), Ministry of Environment (MOE) of the Republic of Korea, grant number NIER-2018-03-01-200. The authors would like to thank researchers invited in the special session for International Symposium for 25th Anniversary of World Water Day 2017 for their insightful comments and suggestions.

\section{Author Contributions}

D.R.J. (Researcher) took the lead in writing the manuscript. J.H.L. (Senior Researcher) were in charge of overall direction and planning. C.H.L. (Researcher) wrote and revised the manuscript. I.A.H. (Senior Researcher) conceived the study and revised the manuscript. C.K.K. (Researcher) designed the experiment and analysed the data. S.D.M. (Researcher) performed the experiment and calculation. S.H.K. (Researcher) verified the analytical methods and carried out the experiment. M.S.P. (Researcher) verified the analytical methods and carried out the experiment.

\section{References}

1. Washington State Department of Ecology. Sediment Management Standards Rule Revisions Chapter 173-204 WAC;Washington State Department of Ecology: Olympia, WA, USA; 2013.

2. Persaud D, Hayton A, Jaagumagi R. Guidelines for the Protection and Management of Aquatic Sediment Quality in Ontario: Report; Water Resources Branch, Ontario Ministry of the Environment: Toronto, ON, Canada; 1992.

3. Long ER, Field LJ, MacDonald DD. Predicting toxicity in marine sediments with numerical sediment quality assessment guidelines. Environ. Toxicol. Chem. 1998;17:714-727.

4. Smith SL, McDonald DD, Keenleyside KA, Ingersoll CG, Field J. A preliminary evaluation of sediment quality assessment values for freshwater ecosystems. J. Great Lakes Res. 1996;22: 624-638.

5. Barrick R, Becker S, Brown L, Beller H, Pastorok R. Sediment-Quality-Values Refinement. Vol. 1. Update and Evaluation of Puget Sound AET (Apparent Effects Threshold); Final Report Pb-89-200398/XAB; PTI Environmental Services: Bellevue, WA, USA; 1988

6. MacDonald DD, Ingersoll CG, Berger TA. 2000. Development and evaluation of consensus-based sediment quality guidelines for fresh water ecosystems. Archives of Environ Toxicol Chem. 2009;39:20-31.

7. National Institute of Environmental Research NIER. Baseline concentrations of heavy metals in river sediments in Korea. Sejong City: Ministry of Environment; 2011.

8. Jun-Ho P, Dong-Hyun C, Geun J. Ecotoxicological study on the effects of acidification in artificial stream on the drifting behavior of Gammarus sobaegensis. J. Environ. Biol. 2000;18: 153-161.

9. Jun-Ho P, Dong-Hyun C, Geun J. Ecotoxicological characteristics 
of Gammarus sobaenensis Uéno by acute and chronic $\mathrm{pH}$ depression on artificial static waters. J. Environ. Biol. 2000;18:377-385.

10. National Institute of Environmental Research NIER. Study on the derivation and application of environmental quality guidelines for freshwater sediments (II); 23 March 2014; Sejong City. p. 50-53.

11. United States Environmental Protection Agency USEPA. Methods for Measuring the Toxicity and Bioaccumulation of Sediment-Associated Contaminants with Freshwater Invertebrates. 2nd ed EPA 600/R-99/064. Washington DC, USA; 2000.

12. National Institute of Environmental Research NIER. Study on the background concentration in lake sediments; 18 March 2013; Sejong City.

13. Batley GE, Stahl RG, Babut MP, et al., Scientific underpinnings of sediment quality guidelines. USEPA; 2005.

14. MacDonald DD, Carr RS, Calder FD, Long ER, Ingersoll CG. Development and evaluation of sediment quality assessment guidelines for Florida coastal waters. Ecotoxicology 1996;5: 253-278.

15. Wenning RJ. Use of Sediment Quality Assessment Guidelines and Related Tools for the Assessment of Contaminated Sediments, Chapter 3; Society of Environmental Toxicology and Chemistry (SETAC); 2005.

16. Long ER, Dutch M, Aasen S, Welch K, Hameedi MJ. Spatial extent of degraded sediment quality in Puget Sound (Washington State, USA) based upon measures of the sediment quality triad. Environ. Monit. Assess. 2005;111:173-222.

17. Gunnarsson RK, Lanke J. The predictive value of microbiologic diagnostic tests if asymptomatic carriers are present. Stat. Med. 2002;21:1773-1785.

18. Douglas WS, Reiss M, Lodge J, 2005. Evaluation of sediment quality guidelines for management of contaminated sediments in New York-New Jersey Harbor. In Use of Sediment Quality Guidelines and Related Tools for the Assessment of Contaminated Sediments(SERAC); 2005.

19. USACE, Dredged material evaluation and disposal procedures: A users manual for the Puget Sound Dredged Disposal Analysis (PSSDA) Program. Seattle (WA): US Army Corps of Engineers; 2000.

20. Long ED, Ingersoll CG, MacDonald DD. Calculation and uses of mean sediment quality guideline quotients: a crtical review. Environ. Sci. Tech. 2006;40:1726-1736.

21. MacDonald DD, Ingersoll CG, Moore D, Carr RS, Calcasieu Estuary remedial investigation/feasability study(RI/FS): Baseline ecological risk assessment (BERA); Technical report plus appendices; Contract No. 68-W5-0022; Document control number 3282-941-RTZ- RISKZ-14858; Prepared for CDM Federal Programs Corporation and U.S. Environmental Protection Agency: Dallas, USA; 2002.

22. Fairey R, Long ER, Roberts CA, et al. An evaluation of methods for calculating mean sediment quality guideline quotients as indicators of contamination and acute toxicity to amphipods by chemical mixtures. Environ. Toxico.l Chem. 2001;20: 2236-2286.

23. Bay SM, Weisberg SB. Framework for interpreting sediment quality triad data. Integ. Environ. Assess Manage. 2010;8: 589-596.

24. Long ED, Dutch M, Partrige V, Weakland S, Welch K, Revision of sediment quality triad indicators in Puget Sound (Washington, USA): I. A sediment chemistry index and targets for mixtures of toxicants. Integ. Environ. Assess Manage. 2012;9:31-49. 